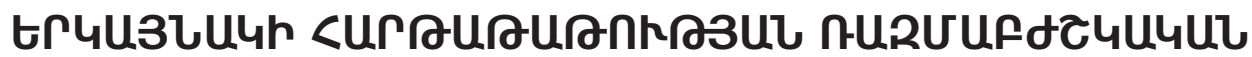

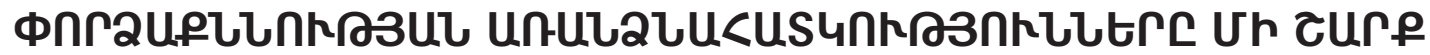 trunutrnhU
}

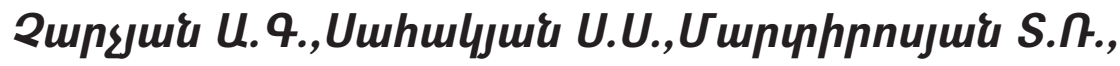 \\ Umpnujwir U.9., Uwhuljuir U.U.
}

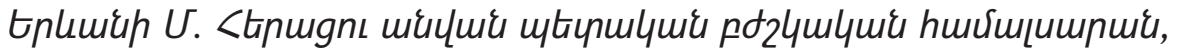

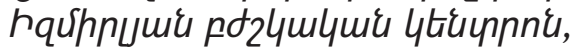
tplimi, <mјшичмия

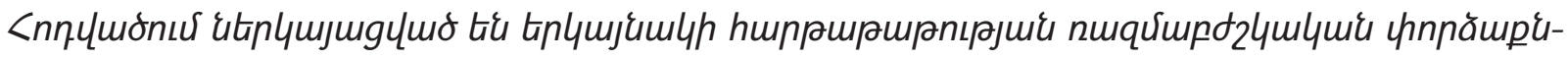

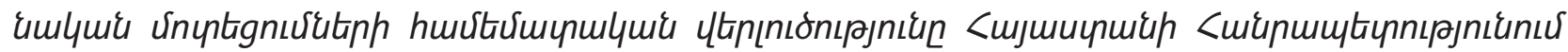

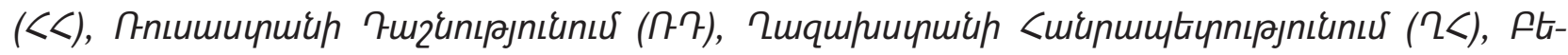

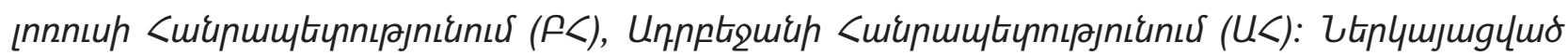

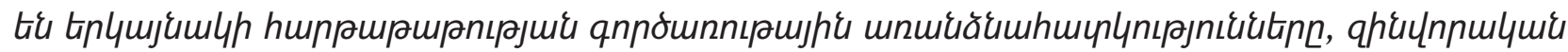

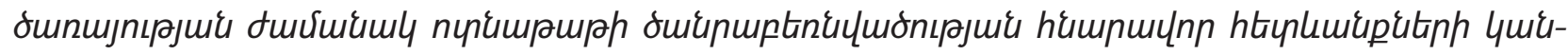

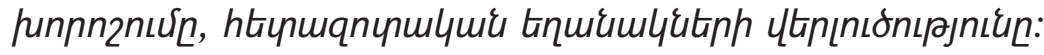

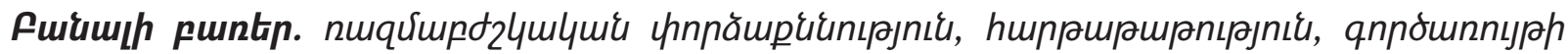

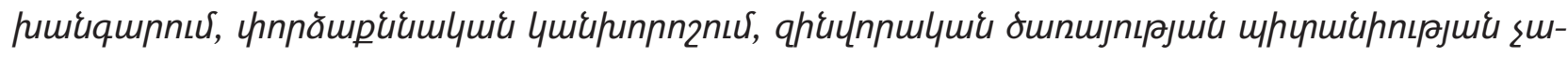
unnnnzhsitin:

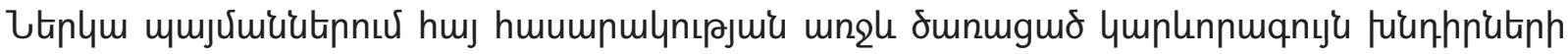

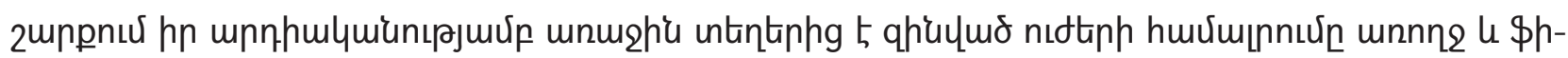

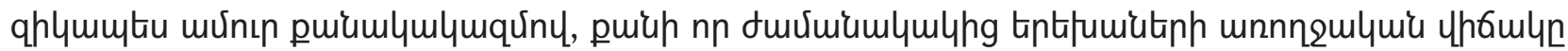

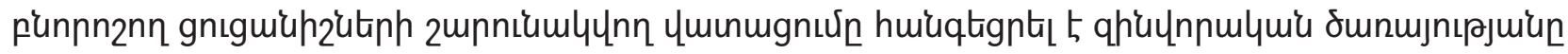

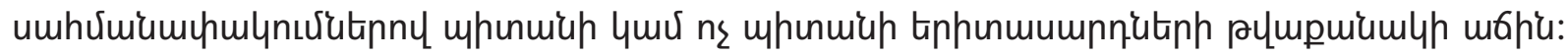

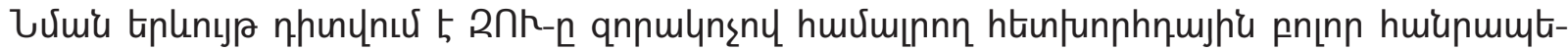
unnเpjnıนüunnuर [1-2]:

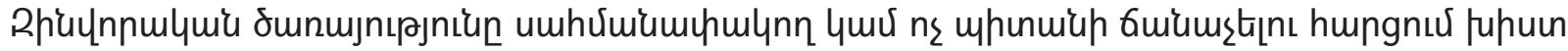

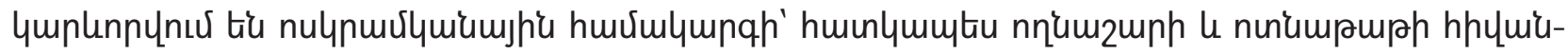

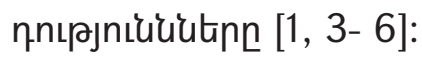

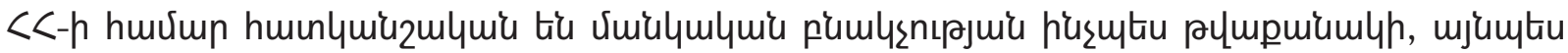

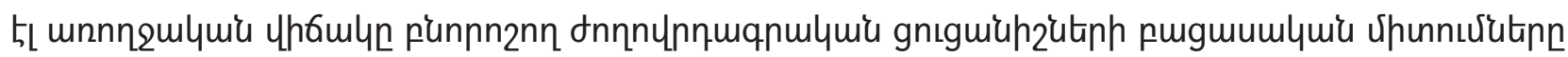

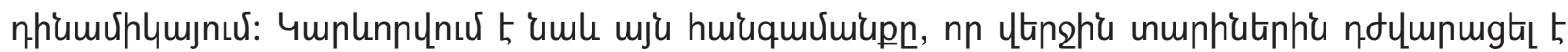

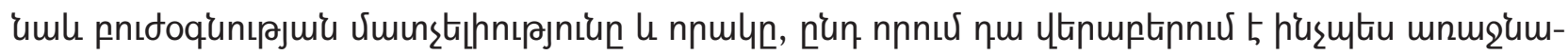

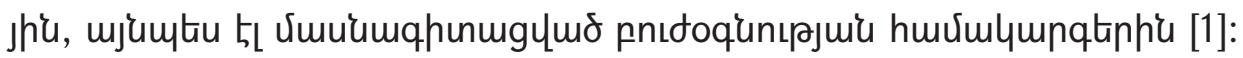

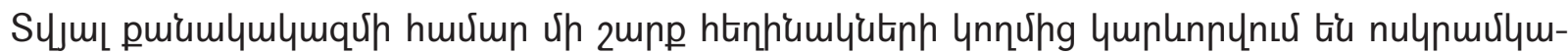

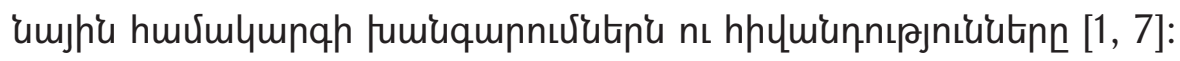

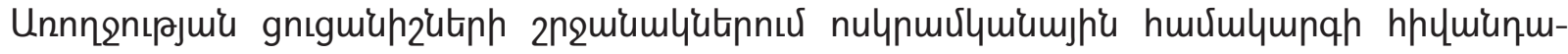

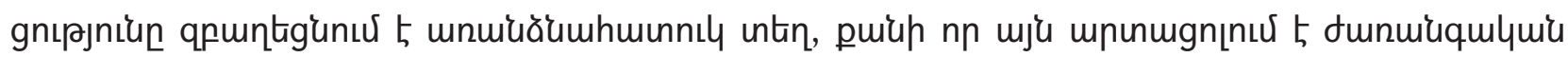

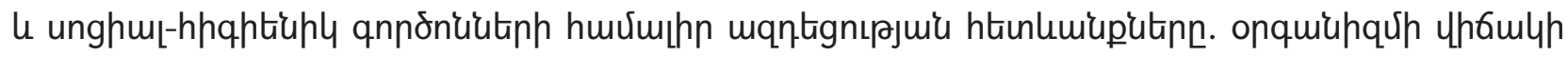

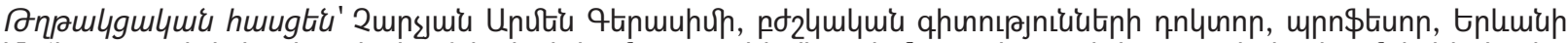

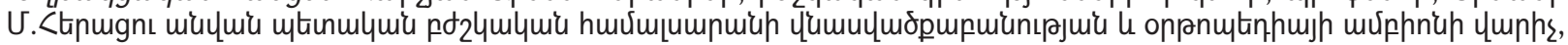
hqûn
} 


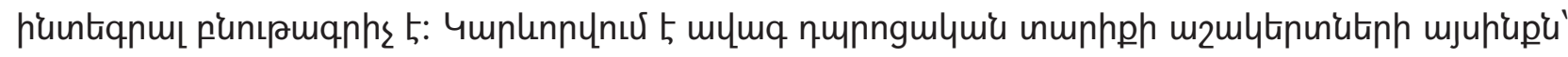

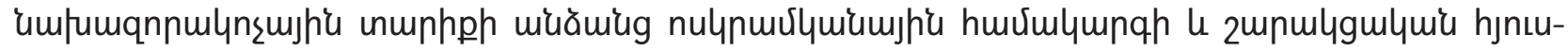
чmoph uh6ulyn [1, 8-9]:

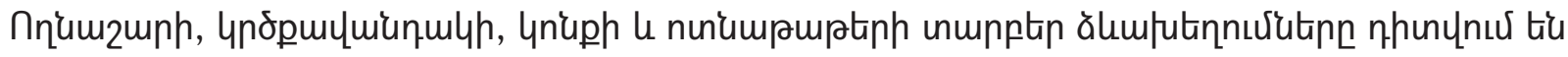

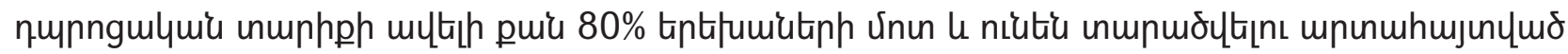
uhunnuर [1, 10]:

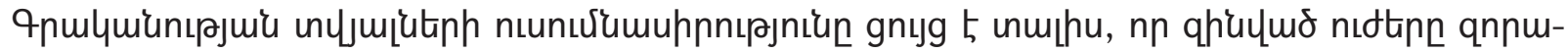

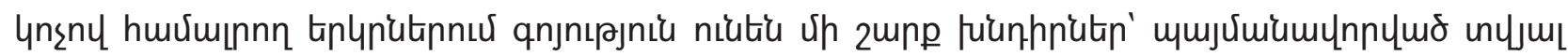

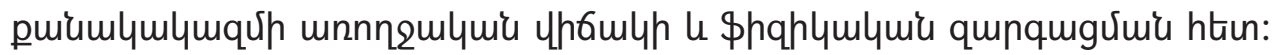

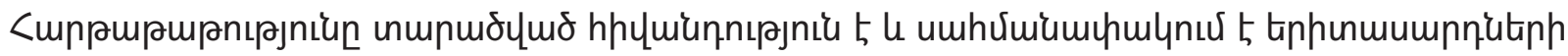
qnnulynę qhäumo nıdtip $[1,11]$ :

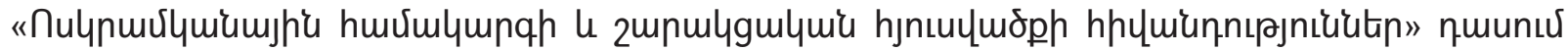

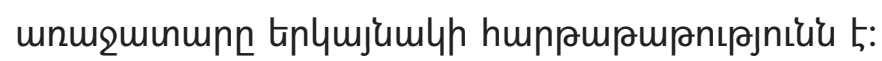

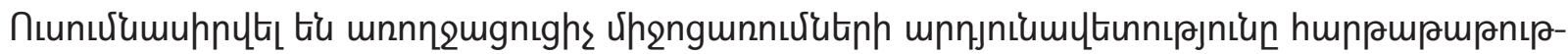

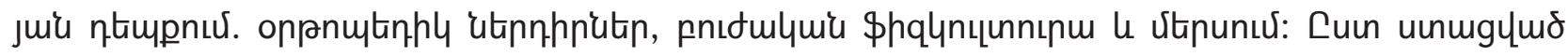

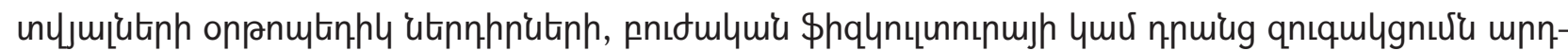

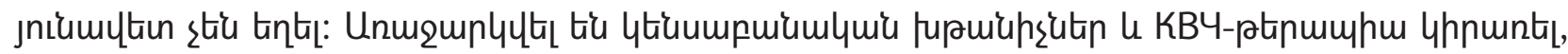

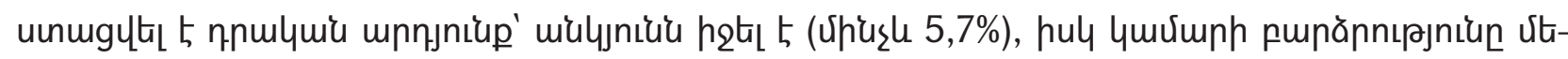

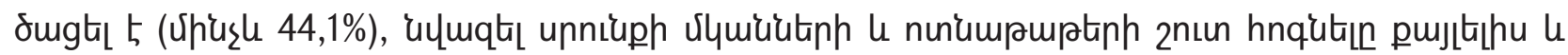

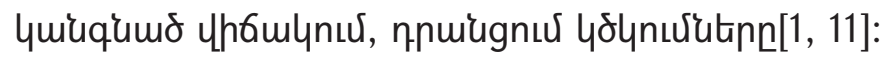

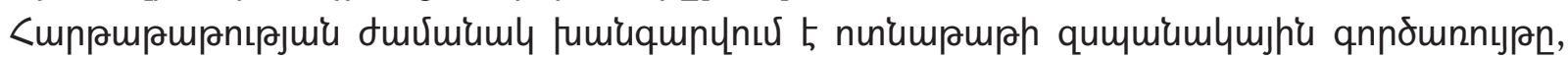

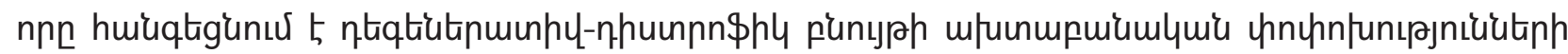

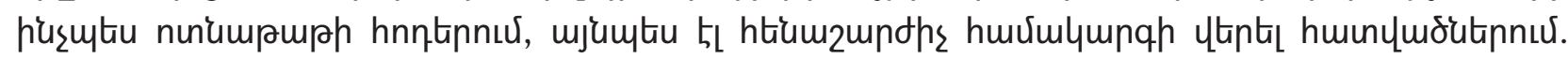

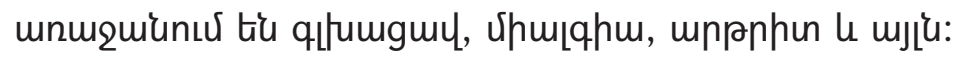

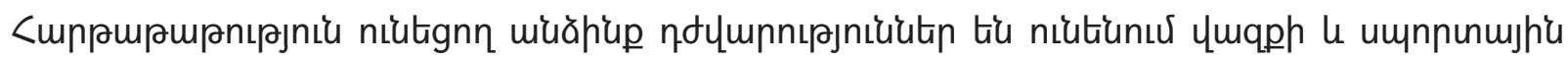

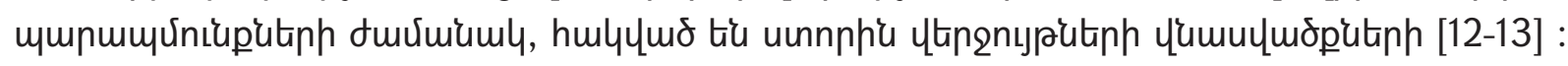

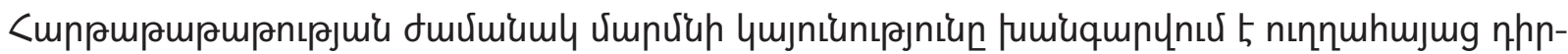

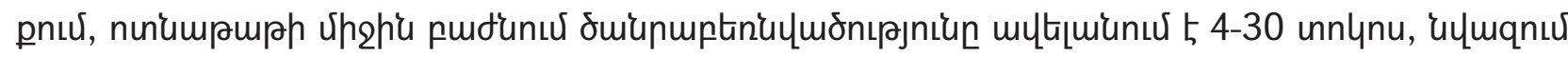

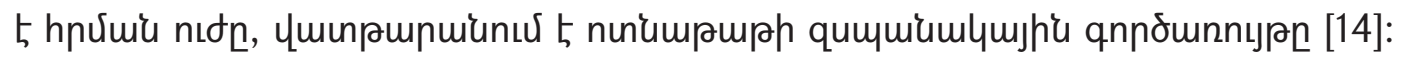

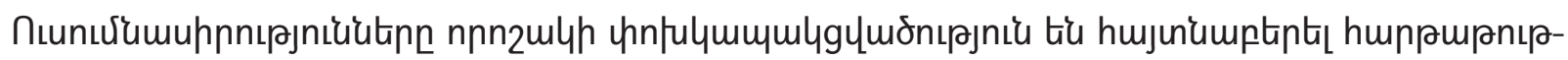

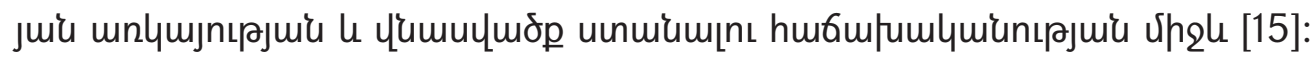

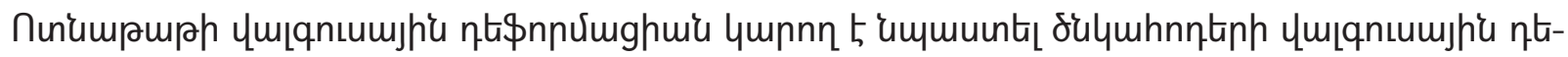
\$nnưughump ălumųnoưừn [16]:

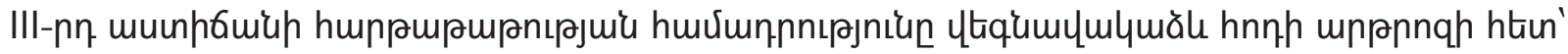

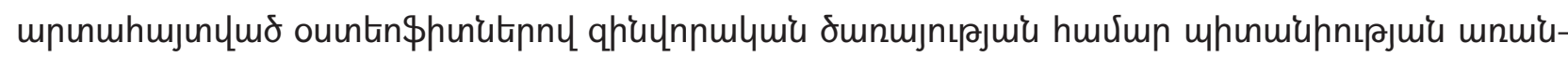

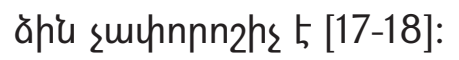

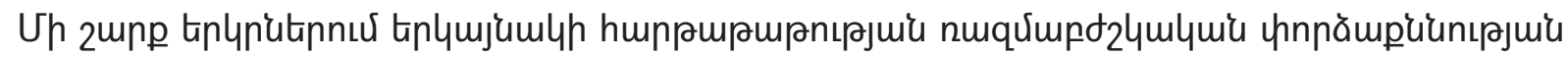

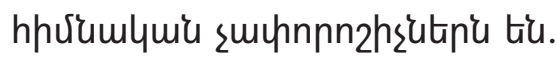

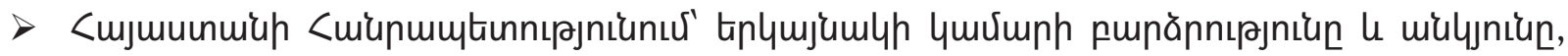

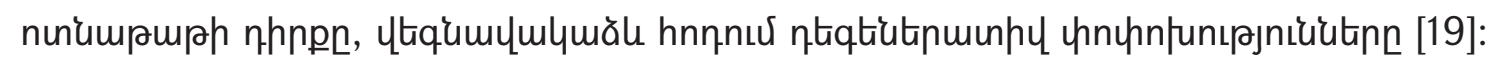

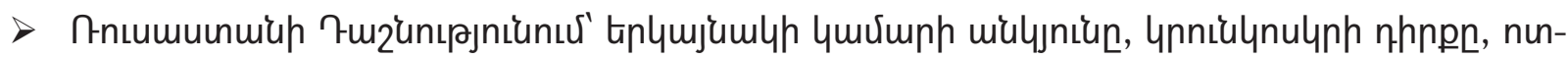

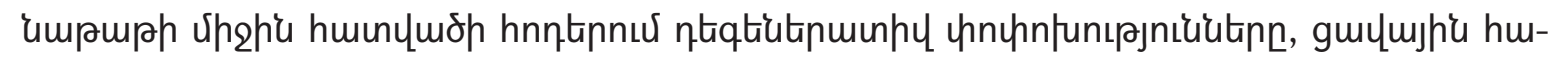
viufuunuin2n [20]: 


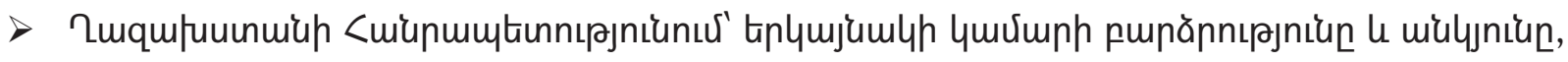

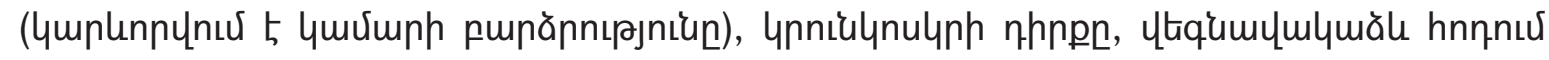

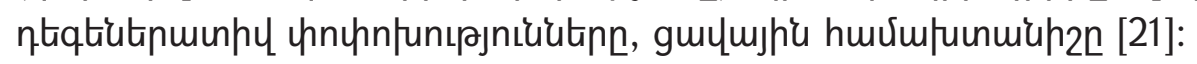

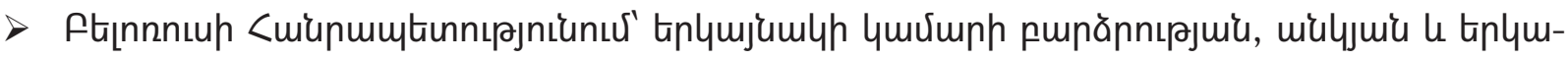

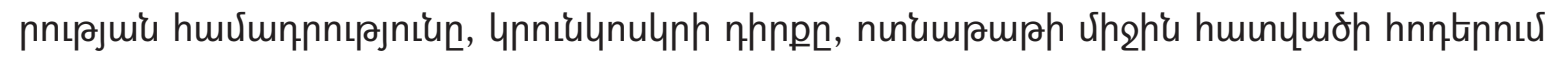

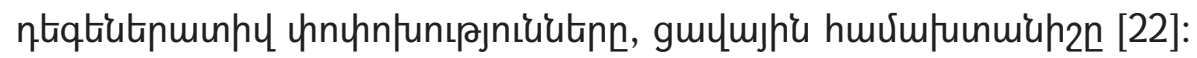

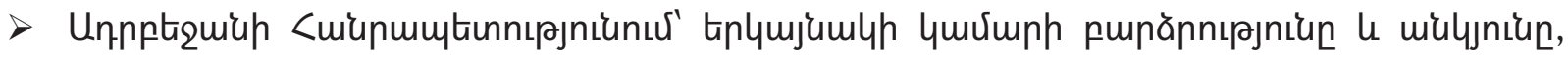

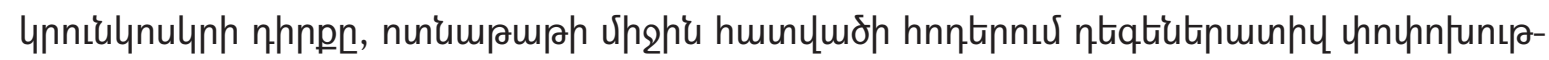

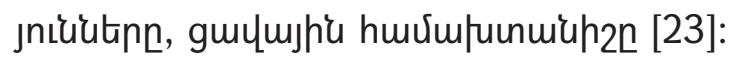

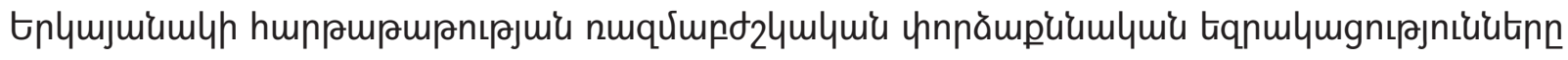
unnuntu tü.

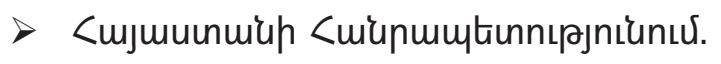

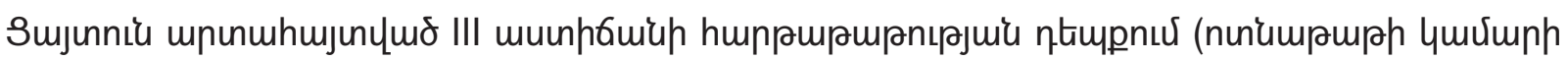

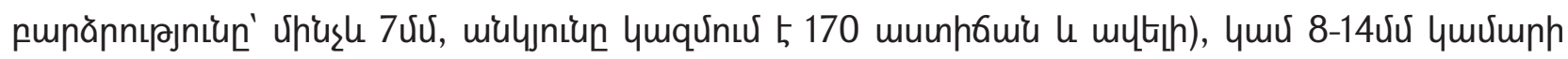

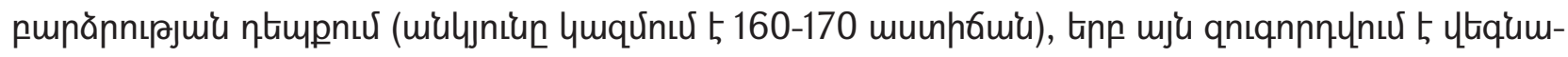

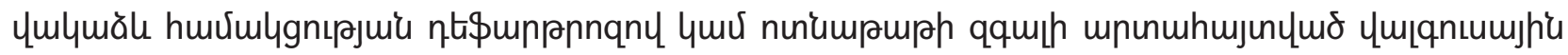

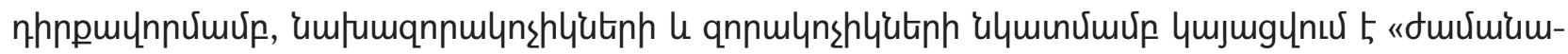

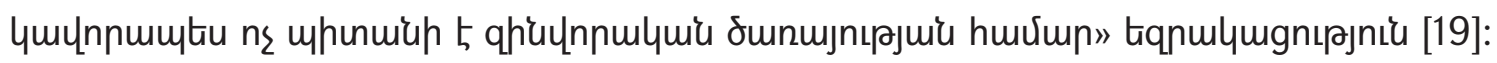

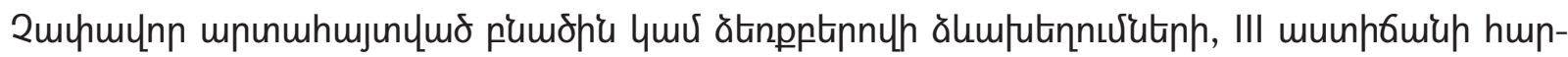

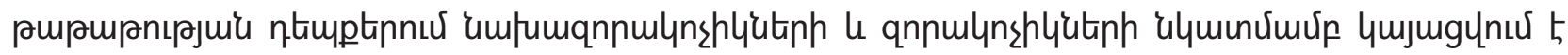

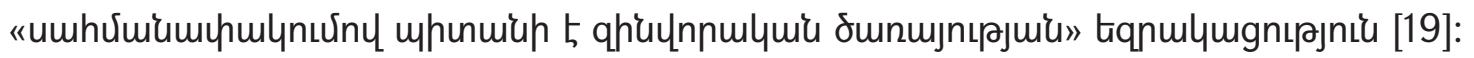

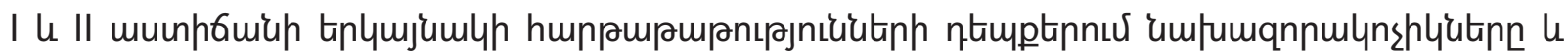

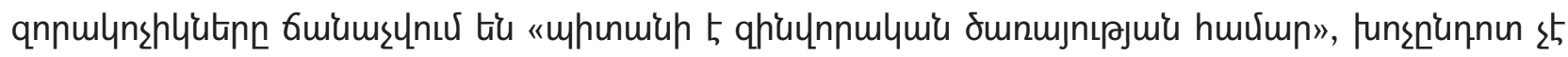

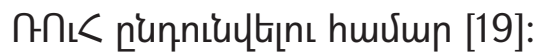

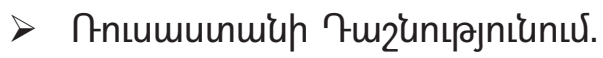

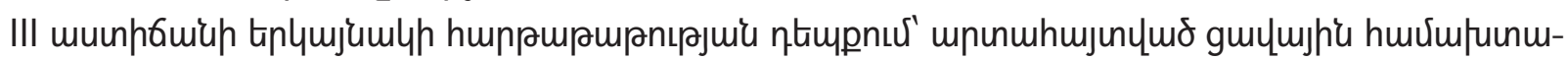

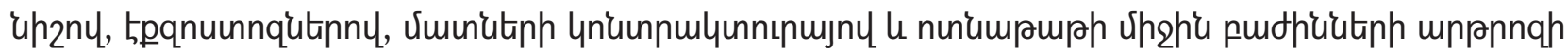

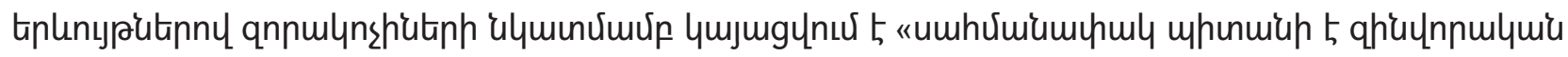

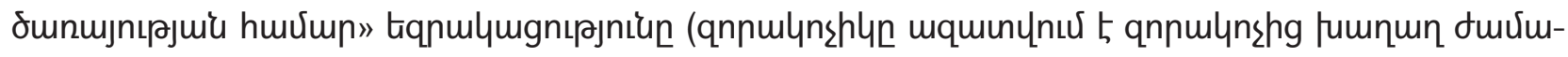
imly [20]:

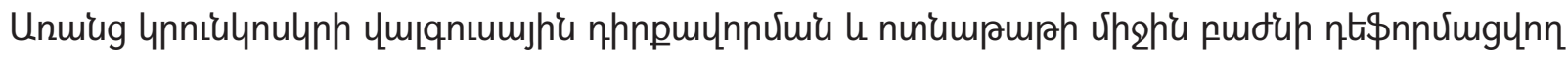

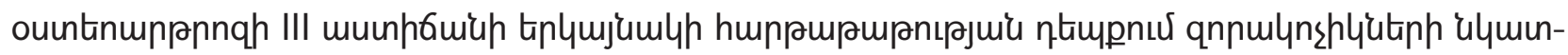

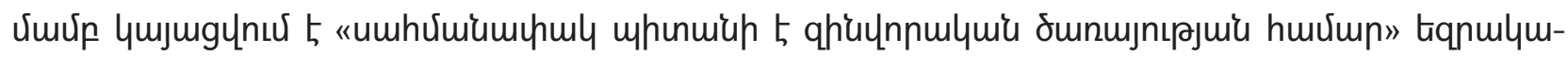
gnıpjnเu [20]:

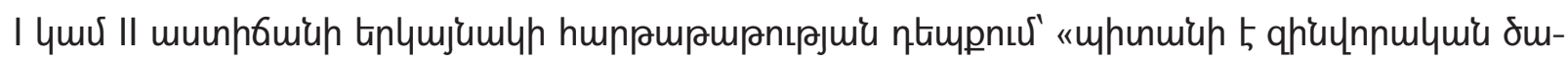

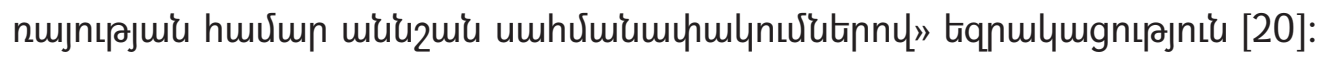

$>$ Ququifuuinuiuh <

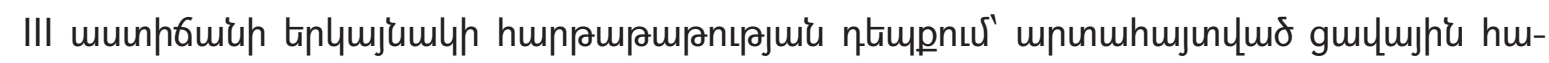

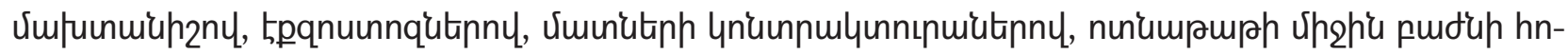

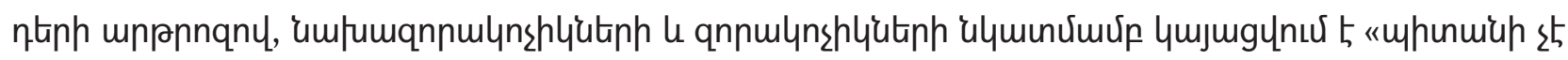

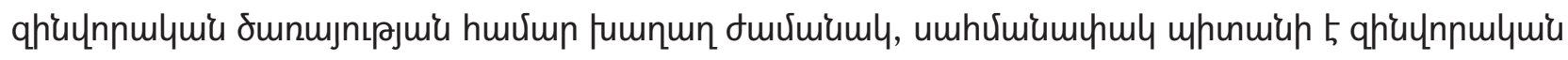

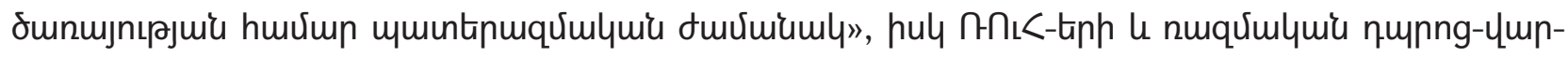

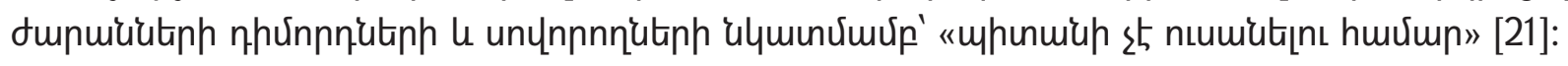




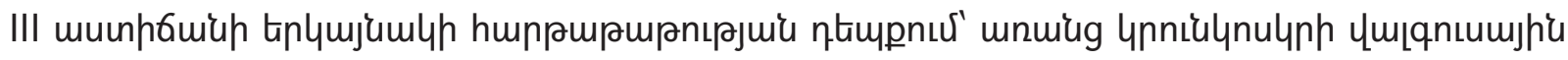

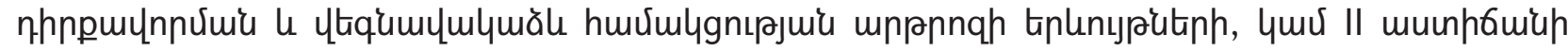

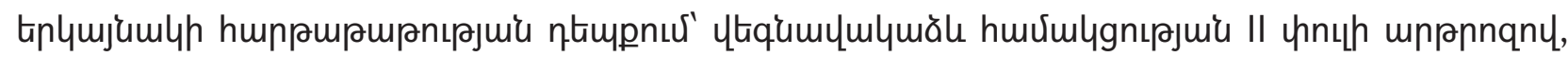

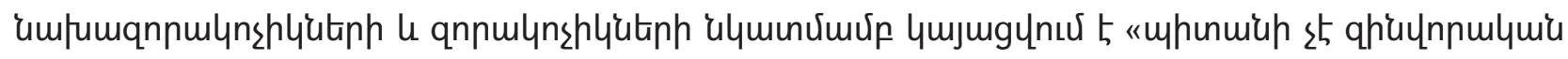

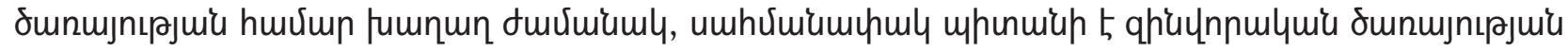

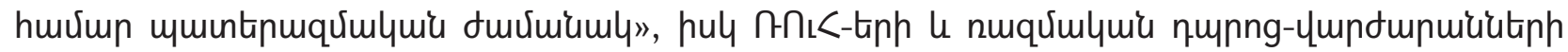

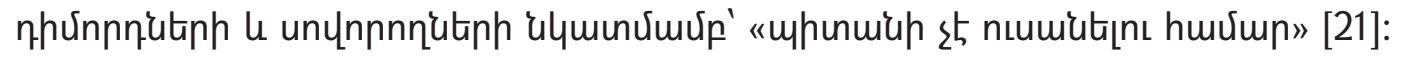

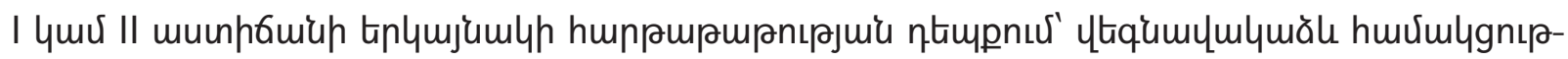

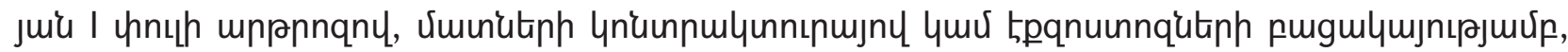

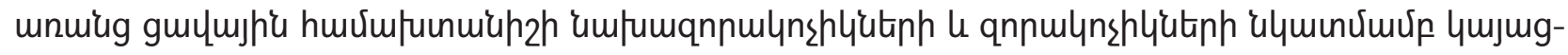

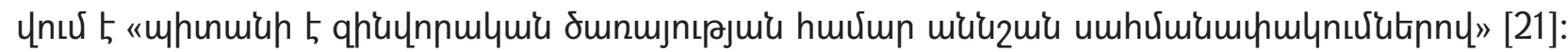

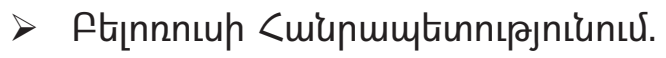

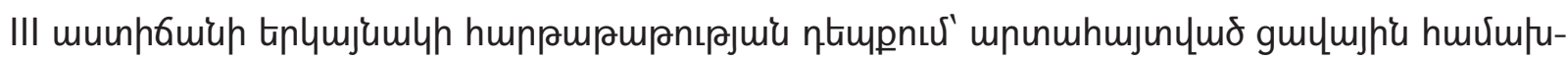

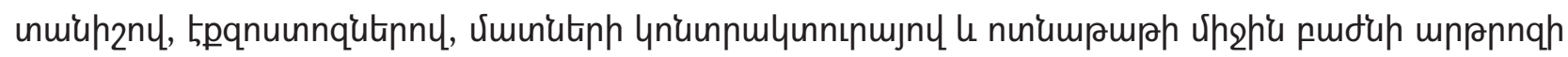

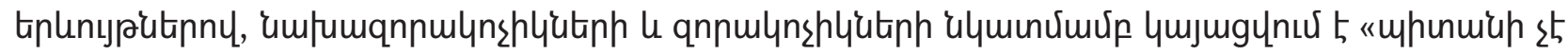

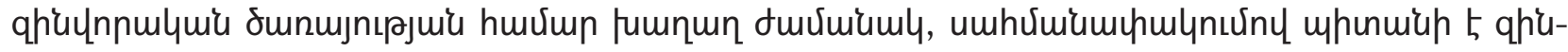

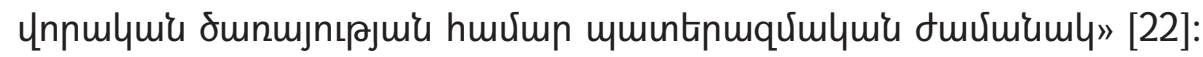

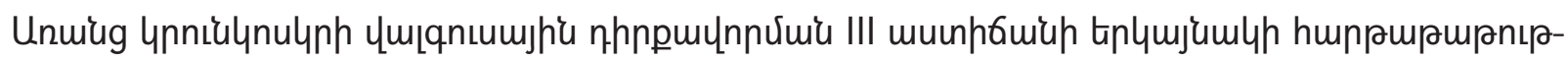
ju'u

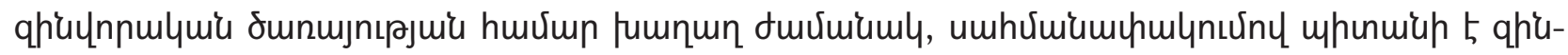

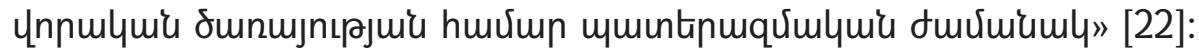

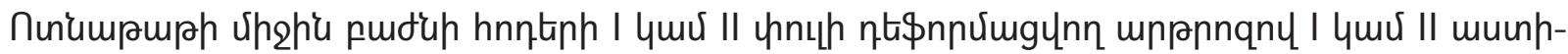

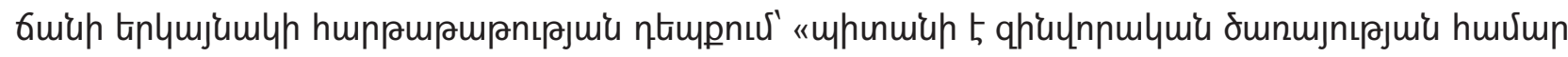

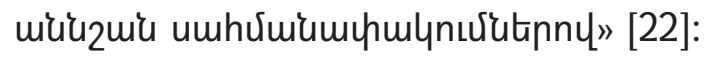

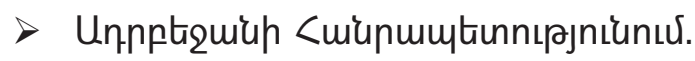

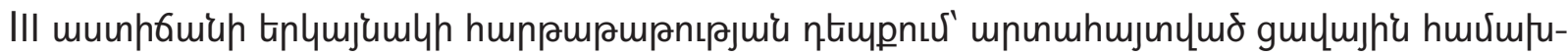

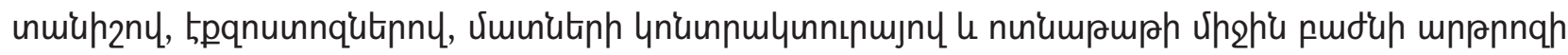

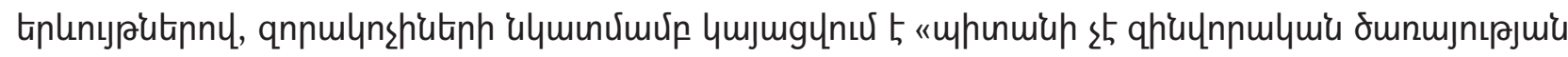

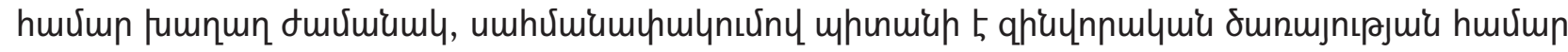

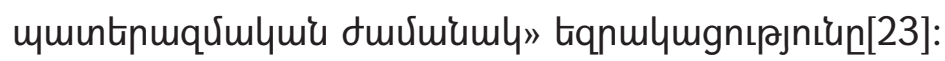

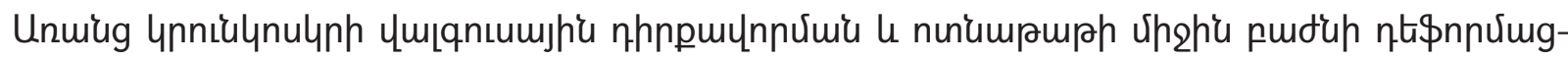

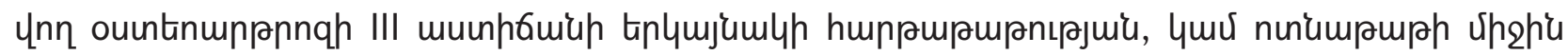

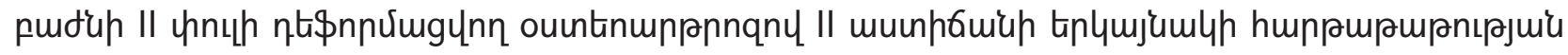

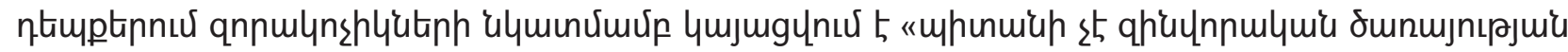

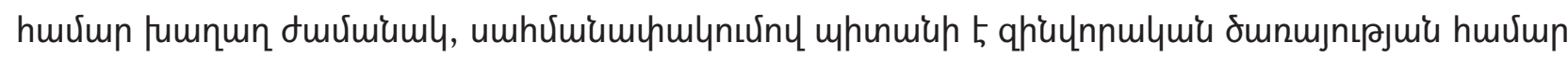

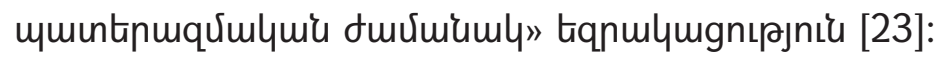

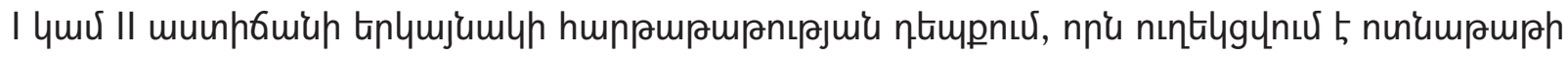

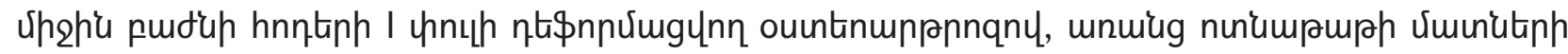

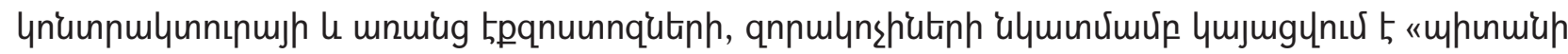

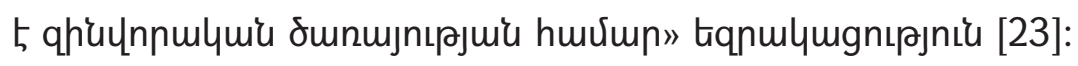

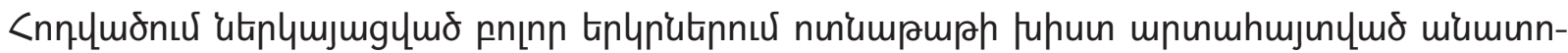

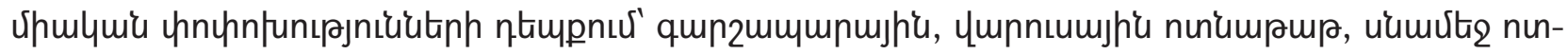

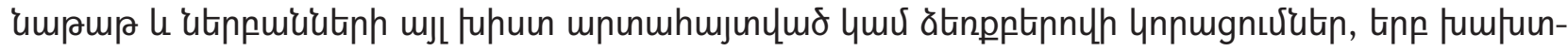




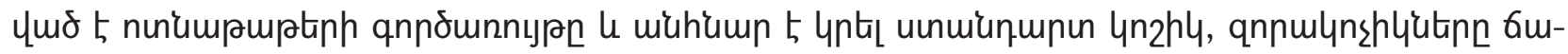

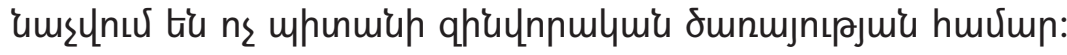

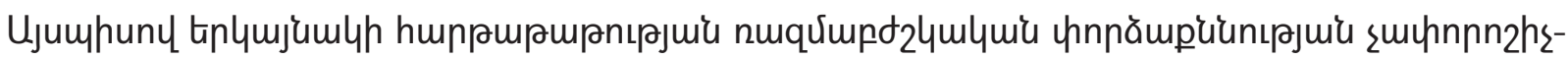
utinu tiu'

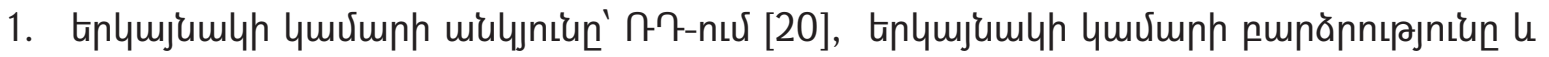

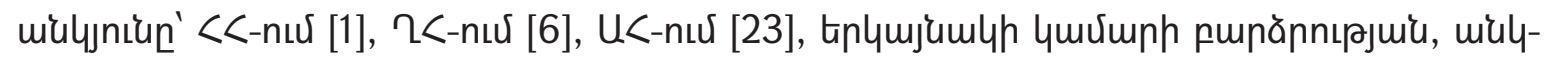

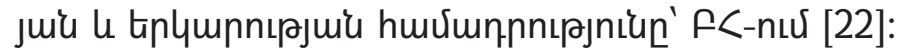

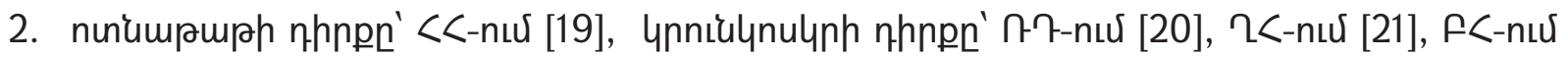
[22], U<-nuर [23]:

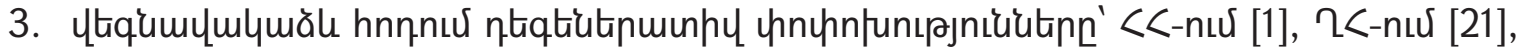

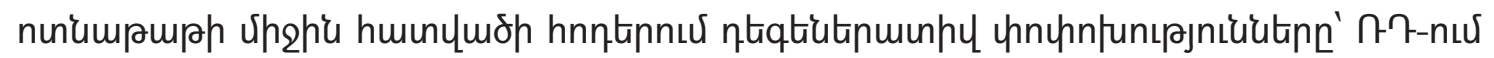
[20], f<-nuर [22], U<-nuर [23]:

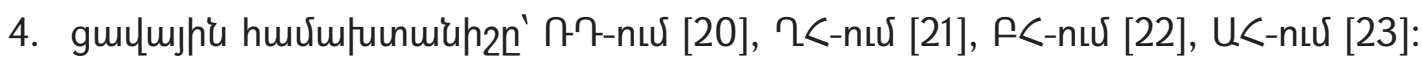

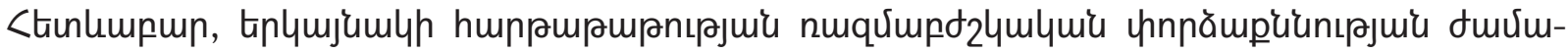

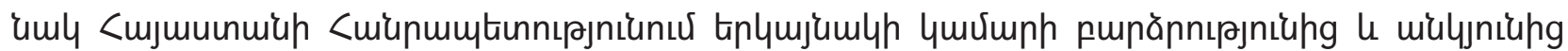

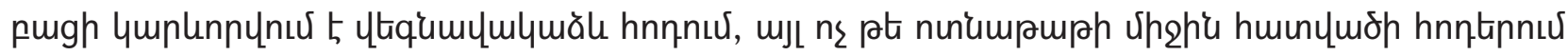

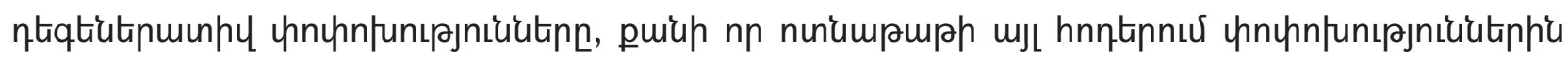

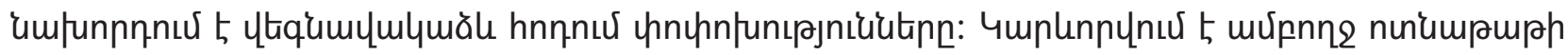

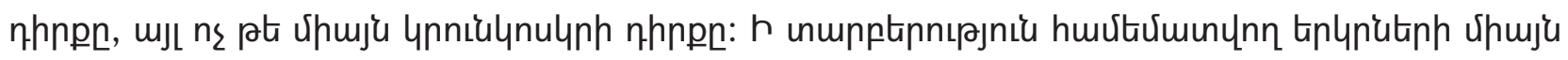

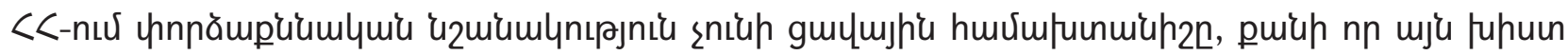
unıpjtyunhy surunnnzhs 5 [19]:

\section{9puluiuntpjuil guily}

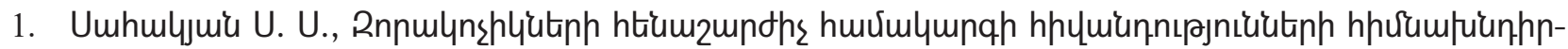

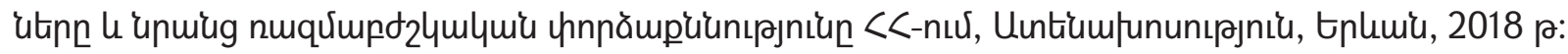

2. Ахмерова С.Г., Ляхович А.В., Федин Э.Е. Показатели годности к военной службе, мотивационные установки и состояние здоровья юношей допризывного и призывного возраста //Вестник новых медицинских технологий. Тула, 2010. Т. XVII. №3.

3. Гребова Л.П. Лечебная физическая культура при нарушениях опорно-двигательного аппарата у детей и подростков // Учеб пособие Гребова Л.П. М.: 2006.

4. Чекалова Н.Г., Силкин Ю.Р., Шапошникова М.В., Чекалова С.А. и соавт. Семья и этапы профилактики нарушений костно-мышечной системы детей // Медицинский альманах. 2008. №5.

5. Чекалова Н.Г. Гигиенические основы мониторинга костно-мышечной системы школьников // Дисс...д.м.н. Нижний Новгород. 2011.

6. Чекалова Н.Г., Силкин Ю.Р., Халецкая О.В., Чекалова С.А. и соавт. Врачебный контроль за физическим воспитанием современных школьников // Всероссийский конгресс по школьной и университетской медицине с международным участием: материалы. М., 2010.

7. Храмцов П.И., Седова А.С., Березина Н.О., Вятлева О.А. Медико-педагогические и нейрофизиологические предпосылки формирования у обучающихся мотивации к занятиям физической культурой // Гигиена и санитария. 2015. №1.

8. Кучма В.Р., Сухарёва Л.М., Ямпольская Ю.А. Тенденции роста и развития московских школьников старшего подросткового возраста на рубеже тысячелетий. Гигиена и санитария. 2009. № 2. 
9. Баранов А.А., Кучма В.Р., Рапопорт И.К. Стратегия «Здоровье и развитие подростков России» как инструмент международного взаимодействия в охране здоровья детей. // Российский педиатрический журнал. 2011. №4.

10. Бубновский С.М. Профилактика заболеваний костно-мышечной системы у школьников средствами кинезитерапии // Дисс...д.м.н. М.: 2007.

11. Куликов В.В., Никитин В.Ф., Клепиков С.В., Катанцев А.В. Диагностика и военно-врачебная экспертиза при плоскостопии // Уч. метод, пособ. М. 2004.

12. Menz HB. Alternative techniques for the clinical assessment of foot pronation / H. B. Menz. Journal of the American Podiatric Medical Association.1998.

13. Soomekh DJ. Pediatric and adult fl atfoot reconstruction: subtalar arthroereisis versus realignment osteotomy. surgical options / D. J. Soomekh, B. Baravarian. Clin Podiatr Med Surg. 2006.

14. Basmajian JV. Th e Role of Muscles in Arch Support of the Foot an electromyographic study/ J. V. Basmajian, G. Stecko. Th e Journal of Bone \& Joint Surgery. 1963.

15. McPoil TG. Eff ect of using truncated versus total foot length to calculate the arch height ratio / T. G. McPoil [et al.]. Foot (Edinburgh, Scotland). 2008.

16. Vukasinović Z. Flat feet in children /Z. Vukasinovic' [et al.]. Srp Arh Celok Lek. 2009.

17. Hunt AE. Mechanics and control of the flat versus normal foot during the stance phase of walking / A. E. Hunt, R. M. Smith. Clinical biomechanics (Bristol, Avon). 2004.

18. Nachbauer W. Eff ects of arch height of the foot on ground reaction forces in running / W. Nachbauer, B. M. Nigg. Medicine and science in sports and exercise. 1992.

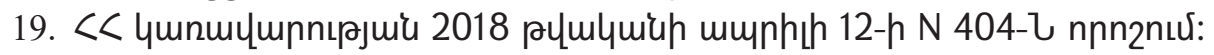

20. Постановление Правительства Российской Федерации от 4 июля 2013 г. № 565 (В редакции постановлений Правительства Российской Федерации от 01.06.2020 № 803)

21. Приказ Министра обороны Республики Казахстан от 29 января 2013 года № 37 (с изменениями по состоянию на 02.02.2018 г.)

22. Постановление министерства обороны Республики Беларусь и министерства здравоохранения Республики Беларусь, 3 января 2020 г. № 1/1

23. Azərbaycan Respublikasi nazirlər kabinetinin 2008-ci il 29 fevral tarixli, 59 nömrəli qərari ilə təsdiq edilmişdir

\section{ОСОБЕННОСТИ ВОЕННО-МЕДИЦИНСКОЙ ЭКСПЕРТИЗЫ ПРОДОЛЬНОГО ПЛОСКОСТОПИЯ В РЯДЕ СТРАН}

Чарчян А.Г., Саакян С.С., Мартиросян Т.Р., Матосян С.Г., Саакян А.С.

В статье представлен сравнительный анализ подходов военно-медицинской экспертизы продольного плоскостопия для следующих стран: Республики Армения, Российской Федерации, Республики Казахстан, Республики Беларусь, Азербайджанской Республики. Представлены функциональные характеристики продольного плоскостопия, прогноз возможных исходов фрункциональной перегрузки стопы во время прохождения военной службы, а также анализ методов исследования.

Ключевые слова: военно-медицинская экспертиза, плоскостопие, фуннциональные нарушения, прогноз экспертизы, критерии годности к военной службе. 


\section{THE SPECIFIC ASPECTS OF THE MILITARY MEDICAL EXPERTISE OF LONGITUDINAL PES PLANUS IN A NUMBER OF COUNTRIES}

\section{Charchyan A., Sahakyan S., Martirosyan T., Mathosyan S., Sahakyan A.}

The comparative analysis of the approaches of military medical expertise of longitudinal pes planus is presented for the following countries: the Republic of Armenia, the Russian Federation, the Republic of Kazakhstan, the Republic of Belarus, the Republic of Azerbaijan. The functional characteristics of the longitudinal pes planus, as well as the prognosis of possible outcomes of functional overload of the foot during military service, as well as analysis of research methods are presented.

Key words: military medical expertise, pes planus, functional impairment, expertise prognosis, criteria of military service suitability.

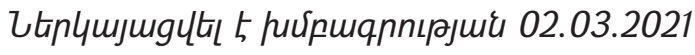

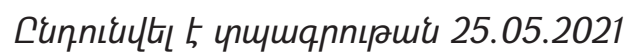

